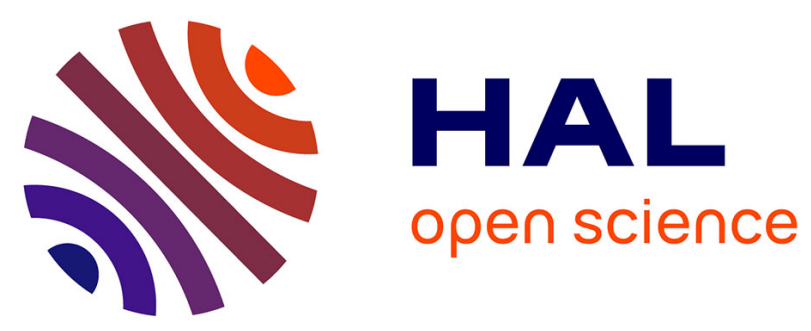

\title{
Respiratory responses and rating of perceived exertion of severely obese adolescents during continuous and intermittent graded walking protocols: Application to cardiorespiratory field tests.
}

Louis Toulouse, Georges Baquet, Elsa Heyman, Thierry Peze, Serge Berthoin, Anne Schill, Christophe Aron, Gautier Zunquin

\section{To cite this version:}

Louis Toulouse, Georges Baquet, Elsa Heyman, Thierry Peze, Serge Berthoin, et al.. Respiratory responses and rating of perceived exertion of severely obese adolescents during continuous and intermittent graded walking protocols: Application to cardiorespiratory field tests.. Journal of Sports Sciences, 2020, 38 (9), pp.1009-1017. 10.1080/02640414.2020.1738701 . hal-02509042

\section{HAL Id: hal-02509042 \\ https://hal.univ-lille.fr/hal-02509042}

Submitted on 16 Mar 2020

HAL is a multi-disciplinary open access archive for the deposit and dissemination of scientific research documents, whether they are published or not. The documents may come from teaching and research institutions in France or abroad, or from public or private research centers.
L'archive ouverte pluridisciplinaire HAL, est destinée au dépôt et à la diffusion de documents scientifiques de niveau recherche, publiés ou non, émanant des établissements d'enseignement et de recherche français ou étrangers, des laboratoires publics ou privés. 
Toulouse L, Baquet G, Heyman E, Pezé T, Berthoin S, Schill A, Aron C, Zunquin G. Respiratory responses and rating of perceived exertion of severely obese adolescents during continuous and intermittent graded walking protocols: Application to cardiorespiratory field tests. J Sports Sci. 2020 Mar 11:1-9.

doi: $10.1080 / 02640414.2020 .1738701$.

PMID: 32160828

\section{Respiratory responses and rating of perceived exertion of severely obese adolescents during continuous and intermittent graded walking protocols: application to cardiorespiratory field tests}

Toulouse L. ${ }^{a *}$, Baquet $\mathrm{G}^{\mathrm{b}}$, Heyman $\mathrm{E}^{\mathrm{b}}$, Pezé $\mathrm{T}^{\mathrm{a}}$, Berthoin $\mathrm{S}^{\mathrm{b}}$, Schill $\mathrm{A}^{\mathrm{c}}$, Aron $\mathrm{C}^{\mathrm{c}}$, Zunquin $\mathrm{G}^{\mathrm{d}}$.

${ }^{a}$ Univ. Littoral Côte d'Opale, Univ. Lille, Univ. Artois, EA 7369 - URePSSS - Unité de Recherche Pluridisciplinaire Sport Santé Société, F-59140 Dunkerque, France

${ }^{b}$ Univ. Lille, Univ. Artois, Univ. Littoral Côte d'Opale, EA 7369 - URePSSS - Unité de Recherche Pluridisciplinaire Sport Santé Société, F-59000 Lille, France

'Service de Soin de Suite et de Réadaptation Adolescents, Hôpital Maritime de Zuydcoote, Zuydcoote, France

${ }^{d}$ Universite de Pau \& des Pays de l'Adour, e2s UPPA, MEPS, Tarbes, France

* TOULOUSE Louis

Univ. Littoral Côte d'Opale, Univ. Lille, Univ. Artois, EA 7369 - URePSSS - Unité de Recherche Pluridisciplinaire Sport Santé Société, F-59140 Dunkerque, France 189b Avenue Maurice Schumann

59140 Dunkerque Cedex

Phone: 00330699213662

E-mail: louis.toulouse@etu.univ-littoral.fr

*BAQUET Georges : georges.baquet@univ-lille.fr

*HEYMAN Elsa : elsa.heyman@univ-lille.fr

*PEZE Thierry : thierry.peze@univ-littoral.fr

* BERTHOIN Serge : serge.berthoin@univ-lille.fr

* SCHILL Anne : a.schill@,ch-zuydcoote.fr

*ARON Christophe : c.aron@ch-zuydcoote.fr

*ZUNQUIN Gautier : g.zunquin@univ-pau.fr 


\title{
Respiratory responses and rating of perceived exertion of severely obese adolescents during continuous and intermittent graded walking protocols: application to cardiorespiratory field tests
}

\begin{abstract}
During $20 \mathrm{~m}$ shuttle tests, obese adolescents may have difficulty achieving maximum cardiorespiratory performance due to the presence of braking-relaunch phases (BRP). Nineteen obese adolescents aged $15.2 \pm 1.5$ years (body mass index $[\mathrm{BMI}]=39.7 \pm 5.9 \mathrm{~kg} \cdot \mathrm{m}^{-2}$ ) performed three graded walking exercises on a $50 \mathrm{~m}$ track at speeds between 3 and $6 \mathrm{~km} / \mathrm{h}$ : a continuous-straight-line protocol (C), a continuous protocol that required turning back every $30 \mathrm{sec}$ (C-BRP) and an intermittent protocol that consisted of successively walking then resting for $15 \mathrm{sec}$ (15-15). Oxygen uptake $\left(\mathrm{VO}_{2}\right)$, aerobic cost of walking $(\mathrm{Cw})$, ventilation (VE) and rating of perceived exertion (RPE) were measured at each stage during the protocols. During C-BRP, the responses were not significantly higher compared with $\mathrm{C}(\mathrm{p}>0.30)$. During $15-15$, the $\mathrm{VO}_{2}, \mathrm{Cw}$ and VE were $\sim 15$ to $25 \%$ lower than during $\mathrm{C}$ beginning at $4 \mathrm{~km} / \mathrm{h}(\mathrm{p}<0.05)$. In obese adolescents, the respiratory impact of sudden directional changes during the $20 \mathrm{~m}$ shuttle-type test appeared to be minor at walking speeds. During the $15-15$ test, the intensity increases more progressively, and this design may encourage obese adolescents to walk further than during a continuous test.
\end{abstract}

Words: 194

Key words: obese, adolescents, $20 \mathrm{~m}$ shuttle run test, intermittent, cardiorespiratory test 


\section{Introduction}

A 40-year follow-up study conducted among thousands of individuals reported that being obese during adolescence is associated with a 3.5-fold increased risk for death from a cardiovascular event, after adjustment for individual characteristics (Twig et al., 2016). Cardiorespiratory fitness (CRF) is one of the main predictors of future cardiovascular risk during adolescence and adulthood (Ortega et al., 2008; Kvaavik et al., 2009) and could reduce the risk of becoming overweight or obese during adolescence (Ortega et al., 2011). Thus, researchers suggest that exercise training programmes should focus on improving CRF rather than losing weight (Barry et al., 2014).

To maximise the benefits of the programme on an individual's CRF, the exercises must be performed at a percentage of the maximal functional respiratory capacity. Thus, the individualisation of an exercise training programme requires assessment of this parameter. This assessment aims to 1) determine the intensity that must be reached during the exercises to obtain the best results and 2) compare the CRF before and after the programme. Due to the high material cost and skills required in laboratory testing, field tests are commonly used in clinical settings to indirectly assess functional respiratory capacities (Quinart et al., 2014). These tests mostly rely on graded walk/run exercises and have been extensively used in paediatric populations, including healthy-weight (Tomkinson et al., 2017) and obese children (Morinder et al., 2009; Vanhelst et al., 2013; Quinart et al., 2014). However, during continuous treadmill testing, Breithaupt et al. (2012) found that many obese adolescents are unable to meet at least two of the maximality criteria: peak of oxygen consumption $\left(\mathrm{VO}_{2 \text { peak }}\right)$, heart rate $>90 \%$ of the theorical maximal value, a respiratory quotient above 1.05 and a feeling of maximal exertion. Moreover, the rating of perceived exertion (RPE) reported by obese adolescents at the end of graded tests corresponds to moderate-vigorous rather than maximal intensities, whether in the laboratory (Marinov et al., 2002; Lazaar et al., 2006) or the field (Rey et al., 2016; Thivel et al., 2017). This finding confirms their difficulty in reaching a state of total exhaustion during a maximal test.

These difficulties may result from the interaction of complex physiological and biomechanical mechanisms. In comparison to their non-obese counterparts, obese adolescents exhibit early lower limb fatigability (Garcia-Vicencio et al., 2015) and reduced muscle oxidative capacities (Salvadego et al., 2010; Lazzer et al., 2013). These limitations lead to early shortness of breath (Mendelson et al., 2012), a state that alters their aerobic performances (Norman et al., 2005). From a biomechanical point of view, excess body weight decreases muscular mechanical efficiency (Rosenbaum et al., 2003) and leads to an approximately $25 \%$ higher average cost of walking $(\mathrm{Cw})$ due to an increased medio-lateral displacement of the centre of gravity (Peyrot et al., 2009). From a psychological point of view, their RPE is apparently lower during a cycling rather than a weight-bearing exercise performed at $75 \%$ of their maximal respiratory capacities (Thivel et al., 2016). This data suggests that walking or running becomes harder than cycling when the intensity crosses a certain level. This phenomenon may be associated with an increased feeling of fatigue or musculoskeletal pain during weight-bearing exercises (O’Malley et al., 2012).

Due to its simplicity, the $20 \mathrm{~m}$ shuttle run test (20 m SRT; Léger et al., 1984) remains the gold standard for field clinical assessment of respiratory fitness in children (Tomkinson et al., 2017). The test consists of successively making round trips over a 20 $\mathrm{m}$ distance at the rate of a progressively more frequent sound signal. However, the presence of a large and increasing number of braking-relaunching phases (BRP) - a 
component within continuous-shuttle tests that requires stopping, turning back and restarting the effort-limits maximal aerobic performance (Berthoin et al., 1994). In athletes, the BRP results in early lactic acidosis (Ahmaidi et al., 1992) and a $\mathrm{VO}_{2}$ increase proportional to the speed (Dellal et al., 2010; Hatamoto et al., 2014). In obese children, the BRP impact during the $20 \mathrm{~m}$ SRT may be accentuated by their excess body weight and could underlie the poor maximal cardiorespiratory performances commonly observed by several authors (Nassis et al., 2005; Klijn et al., 2007; Castro-Pinheiro et al., 2011). Moreover, Quinart et al. (2014) showed that the predicted $\mathrm{VO}_{2 \text { peak }}$ obtained from the adapted $20 \mathrm{~m}$ SRT equation is valid when the BMI is considered, while it is underestimated when the equations proposed by Léger et al. (1984) are used. This study suggests that even an adapted $20 \mathrm{~m}$ SRT would not allow obese adolescents to achieve a valid maximal respiratory performance due to the BRP. However, a current lack of data limits our comprehension of the main cause of this limitation.

Recently, two studies (Rey et al., 2016; Thivel et al., 2017) validated the Spartacus test to assess maximal cardiorespiratory performances in obese adolescents. The Spartacus test is an intermittent, graded and maximal protocol characterised by successive periods of exercise and $15 \mathrm{sec}$ of passive recovery. Initially developed by Rossi et al. (2009) to make aerobic tests less monotonous for children, this test has been successfully used in obese adolescents in order to attenuate the fatigue induced by the sudden directional changes (Rey et al., 2013). Surprisingly, the Spartacus test and the 20 $\mathrm{m}$ SRT elicit similar maximal RPE and heart rate scores in obese adolescents (Rey et al., 2013; Thivel et al., 2017). However, the starting speed used in previous works ( $>7 \mathrm{~km} / \mathrm{h}$ ) could be too high for adolescents with a higher degree of obesity (Kljin et al., 2007; Vincent, 2015). Otherwise, no study has compared respiratory responses or RPE of obese adolescents during a continuous-shuttle (C-BRP) versus continuous straight-line $(\mathrm{C})$ or a C-BRP versus an intermittent 15-15 walking exercise. The latter should be a more suitable form of exercise for obese adolescents.

\section{Objective}

In order to clarify the physiological mechanisms and justify the poor performances during continuous-shuttle-type tests - and to collect new data on the 15-15 exercise modality in obese adolescents - the objective of the present study was to compare respiratory $\left(\mathrm{VO}_{2}\right.$, aerobic cost of walking $[\mathrm{Cw}]$ and ventilation $[\mathrm{VE}]$ ) and perceptual (RPE) responses of this population during three different submaximal graded exercise protocols.

We hypothesised that at the equivalent speed, the respiratory responses and the RPE would be significantly 1) higher during the C-BRP versus the $\mathrm{C}$ protocol; 2) lower during the intermittent protocol (15-15) versus the C-BRP protocol; 3 ) lower during the $15-15$ versus the $\mathrm{C}$ protocol. Our secondary hypothesis was that the relationship between $\mathrm{RPE}$ and $\mathrm{VO}_{2}$ will be stronger during both continuous protocols compared to the intermittent one.

\section{Material and methods}

\section{Participants}

Male and female obese adolescents from Zuydcoote Maritime Hospital's Rehabilitation Care Unit (France) were included in this study. The adolescents were hospitalised in groups of 6 to 8 individuals for 2 months (full-time accommodation from Monday to Friday) as part of a multidisciplinary management of their obesity. The inclusion criteria were: age between 12 and 17 years and obesity defined by a body mass index (BMI) located above the $97^{\text {th }}$ percentile of the French curves (Rolland-Cachera et al., 1991). 
Each participant completed a total of four visits. During the first visit, the protocol was presented to participants and their parents. During this session, height and weight were measured using a stadiometer and an impedance balance (TANITA DC-360 model) in order to calculate BMI, BMI Z-score and body composition. Ethical approval was obtained for this study by a local ethical committee. Information about the aims of this study was provided to parents and adolescents. All participants provided written informed consent to participate in the study. The research was conducted in accordance with the Declaration of Helsinki (2013).

\section{Experimental procedure}

During each follow-up visit, participants performed one of the three graded walking protocols (see Figure 1); each lasted 12 min, divided into four 3-min stages. Such a delay was considered sufficient to achieve a ventilatory steady state in this population, because children have faster oxygen uptake kinetics at exercise onset (Fawkner et al., 2003), and obesity does not affect pulmonary gas exchange capacities in children (He et al., 2009). The selected speeds were $3,4,5$ and $6 \mathrm{~km} / \mathrm{h}$, which correspond to $0.83,1.11,1.39,1.67$ $\mathrm{m} . \mathrm{s}^{-1}$, respectively. Theses velocities were previously used to calculate $\mathrm{Cw}$ in obese adolescents (Peyrot et al., 2009). In order to guide the participants, pads were placed at regular intervals $(4.17 \mathrm{~m})$ that corresponded to the distance covered in $15 \mathrm{sec}$ at a speed of $1 \mathrm{~km} / \mathrm{h}$. A sound was emitted every $15 \mathrm{sec}$, a feature that allowed the participants to adjust their speed during the test.

For each participant, the exercises were performed over a period (at most) of 1 week, in a randomised order, at the same time of day (between 09:00 and 12:00) and interspersed by at least $24 \mathrm{~h}$. The $\mathrm{C}$ protocol - the control condition-consisted of walking along the track without sudden directional changes at the target speeds. The $\mathrm{C}$ BRP comprised walking continuously while turning back to the opposite direction every $30 \mathrm{sec}$ (two signals). The BRP were performed according to the instructions provided during the familiarisation session (Hatamoto et al., 2014). The instructions were to pivot inwards while leaning on their strongest foot in order to minimise balance loss during the movement. Instead of classic shuttle-type protocols with higher and increasing BRP numbers during the test, we used a continuous-shuttle protocol with two BRP per min to ensure that all participants would be able to complete the protocol. The intermittent 1515 protocol consisted of successively walking, resting, walking back to the opposite direction and then resting. At the end of a 15-sec exercise period, the participant had to respect a 15-sec passive recovery period and then start again in the opposite direction at the next signal. The participants were accompanied by an investigator throughout the exercises to ensure compliance with the protocol. The 15-15 modality was selected because of its use during the Spartacus test.

*** Figure 1 near here $* * *$

\section{Data collection}

\section{Oxygen consumption}

During all tests, the participants wore a respiratory gas analyser (Cosmed $\mathrm{K} 4 \mathrm{~b}^{2}$, Italy) that was first calibrated according to the manual instructions. Prior to the start of the first exercise, the respiratory responses $\left(\mathrm{VO}_{2}, \mathrm{Cw}\right.$ and $\left.\mathrm{VE}\right)$ associated with standing were retained as the mean values measured within the last 10 min of standing (this time would be the minimal delay required to reach a steady state $\mathrm{VO}_{2}$ at rest; Compher et al., 2006). 
During exercises, $\mathrm{VO}_{2}, \mathrm{Cw}$ and $\mathrm{VE}$ were averaged over the last $30 \mathrm{sec}$ of each 3 -min stage for $\mathrm{C}$ and $\mathrm{C}-\mathrm{BRP}$ and over the last two 15-sec exercise periods for the 15-15 protocol.

$R P E$

The RPE was assessed by the participants during the last $30 \mathrm{~s}$ of walking for each stage. The score was based on a scale adapted to obese children (COPE-10, Quinart et al., 2016). The instruction to use the ladder was provided during the familiarisation session and participants were reminded on the day of the test.

\section{Cw calculation}

From the $\mathrm{VO}_{2}$ and speed, the $\mathrm{Cw}$ was calculated for each exercise modality, according to the formula of di Prampero et al. (1986):

$$
\mathrm{CW}=\left[\mathrm{VO}_{2} \text { (speed) }-\mathrm{VO}_{2} \text { (standing) }\right] / \text { speed }
$$

Note: $\mathrm{CW}$ is expressed in $\mathrm{ml} \cdot \mathrm{kg}^{-1} \cdot \mathrm{m}^{-1} ; \mathrm{VO}_{2}$ in $\mathrm{ml} \cdot \mathrm{kg}^{-1} \cdot \mathrm{min}^{-1}$; speed in $\mathrm{m} \cdot \mathrm{min}^{-1}$.

\section{Statistical analysis}

The data were analysed with R software (version 3.5.1). Normality and homogeneity of distributions were checked with the Shapiro-Wilk and the Snedecor F tests, respectively. Differences between sex for age, BMI, total mass, lean body mass and fat mass were tested with Student $t$-tests. Subsequently, the effect of the protocol and speed on $\mathrm{VO}_{2}$ was assessed with a mixed-effects two-way analysis of variance (ANOVA; protocol * speed); repeated measures were used for both factors. Duncan's multirange post hoc test was used to compare the $\mathrm{C}$ to the $\mathrm{C}-\mathrm{BRP}$ protocol, the $\mathrm{C}$ to the $15-15$ protocol and the $\mathrm{C}$-BRP to the 15-15 protocol. The same analysis was conducted with $\mathrm{Cw}$ and VE. Finally, the effect of protocol and speed on RPE was analysed with Friedman's ANOVA and Wilcoxon's matched paired tests. The relationship between $\mathrm{RPE}$ and $\mathrm{VO}_{2}$ was tested with a Spearman rank-order correlation coefficient. The threshold for significance was set at $\mathrm{p}<0.05$. 


\section{Results}

*** Table 1 near here ***

\section{Respiratory responses}

$\mathrm{VO}_{2}$ and $\mathrm{CW}$ were plotted against the protocol type and speed in Figure 2 and Figure 3, respectively. There was a significant interaction between the protocol and speed ( $\mathrm{p}<$ 0.001) for all physiological parameters. Post hoc comparisons revealed that this interaction was due to a significant difference between the 15-15 and both the $\mathrm{C}$ and $\mathrm{C}$ $\mathrm{BRP}$ protocols. Indeed, the $\mathrm{VO}_{2}$ and $\mathrm{VE}$ observed during the $\mathrm{C}$ and $\mathrm{C}-\mathrm{BRP}$ protocols were not significantly different from each other $(p>0.36$ and $p>0.30$, respectively, for all speeds). Furthermore, during the $15-15$ protocol, the $\mathrm{VO}_{2}$ and $\mathrm{VE}$ were 15 to $25 \%$ lower than during $\mathrm{C}$ at 4,5 and $6 \mathrm{~km} / \mathrm{h}(\mathrm{p}<0.05, \mathrm{p}<0.01$ and $\mathrm{p}<0.001$, respectively) and the $\mathrm{Cw}$ at all speeds $(\mathrm{p}<0.001)$.

*** Figure 2 near here $* * *$

*** Figure 3 near here $* * *$

\section{Psychological responses}

RPE data are shown in Figure 4. According to the Friedman's ANOVA, there was no significant interaction between protocol and speed on the RPE. The overall RPE was 0.5 points higher during C-BRP compared to the 15-15 ( $\mathrm{p}<0.05)$. However, RPE was comparable between C-BRP and $C(p=0.51)$ and between $15-15$ and $C(p=0.14)$.

*** Figure 4 near here $* * *$

\section{Relationship between respiratory and psychological parameters during the tests}

Finally, we observed a significant moderate-to-strong correlation between RPE and $\mathrm{VO}_{2}$ regardless of the exercise modality $(\mathrm{p}<0.001$ for the three modalities $)$. Moreover, the correlations were stronger in the $\mathrm{C}(\mathrm{r}=0.64)$ and $\mathrm{C}-\mathrm{BRP}(\mathrm{r}=0.66)$ protocols compared to the $15-15$ protocol $(r=0.49)$. 


\section{Discussion}

The first objective of this study was to measure aerobic and psychological responses during three types of graded exercises in order to identify the potential mechanisms that can limit obese adolescents during a shuttle-type graded test. To our knowledge, this study is the first that compared respiratory responses among three graded walking exercises in severely obese adolescents. The main findings of this study were: 1) The respiratory responses and RPE were not significantly impacted by the presence of two BRP per min at walking speeds in obese adolescents, according to our comparative analysis between the $\mathrm{C}$ and C-BRP protocols; 2) At speeds above $3 \mathrm{~km} / \mathrm{h}$, the $15-15$ modality led to a $15-25 \%$ reduction in respiratory responses, with an accentuating effect of speed.

First, we hypothesised that the presence of BRP during a continuous-graded test would be associated with higher $\mathrm{VO}_{2}, \mathrm{Cw}, \mathrm{VE}$ and $\mathrm{RPE}$ in obese adolescents. Contrary to our expectations, both respiratory and psychological responses were not significantly different between the C-BRP and C protocols, despite the presence of two BRP per min at all speeds. At $6 \mathrm{~km} / \mathrm{h}$, the $\mathrm{VO}_{2}$ reached $17.3 \pm 2.3$ and $17.9 \pm 1.9 \mathrm{ml} \cdot \mathrm{kg}^{-1} \cdot \mathrm{min}^{-1}$ for the $\mathrm{C}$ and C-BRP protocols, respectively. Thus, $\mathrm{VO}_{2}$ only increased $0.6 \mathrm{ml} \cdot \mathrm{kg}^{-1} \cdot \mathrm{min}^{-1}$ during the C-BRP protocol. In obese individuals, the lower limb muscle contractions required to move their body are disproportionately increased because they have to improve their dynamic stability to protect the knee joint (Sheehan et al., 2012). During a continuousshuttle test, the need to slow down, turn back and re-accelerate the body was hypothesised to significantly impact respiratory responses due to an overrecruitment of lower limb muscles. The presented results suggest that respiratory responses are not severely affected by the BRP in obese adolescents during walking. It is possible that for walking speeds, two BRP per min represents an insufficient stimulus to significantly increase $\mathrm{VO}_{2}$, even in severely obese adolescents.

In athletes, the $\mathrm{VO}_{2}$ becomes significantly higher during the $20 \mathrm{~m}$ SRT compared to straight-line running only at speeds above $60 \%$ of the maximal speed reached during the $20 \mathrm{~m}$ SRT (Buchheit et al., 2011). Rey et al. (2016) reported a $\mathrm{VO}_{2 \text { peak }}$ at the end of the $20 \mathrm{~m}$ SRT of $38 \mathrm{ml} \cdot \mathrm{kg}^{-1} \cdot \mathrm{min}^{-1}$ in obese adolescents. Compared to this study, those participants were of a comparable sex distribution (11 girls and 6 boys) but lower corpulence $\left(\mathrm{BMI}=34.0 \pm 5.3\right.$ versus $39.7 \pm 5.9$ in the present study). If $\mathrm{VO}_{2 \text { peak }}$ is estimated at $\sim 30 \mathrm{ml} \cdot \mathrm{kg}^{-1} \cdot \mathrm{min}^{-1}$ in the present population, the intensity of the protocol likely reached $\sim 60 \% \mathrm{VO}_{2 \text { peak }}$ at $6 \mathrm{~km} / \mathrm{h}$, a value that should correspond to the intensity required to detect a significant BRP effect on $\mathrm{VO}_{2}$ during the $20 \mathrm{~m}$ SRT. However, during the $20 \mathrm{~m}$ SRT (or its adapted version for obese children with a starting speed of $4 \mathrm{~km} / \mathrm{h}$, validated by Quinart et al., 2014), the BRP number per min is higher than in our protocol and increases proportionally with the speed of movement: from three at $4 \mathrm{~km} / \mathrm{h}$ to five at $6 \mathrm{~km} / \mathrm{h}$. Considering this difference and the low observed RPE scores, it is possible that the speeds reached during the protocol were insufficient to detect any significant impact of the BRP on respiratory responses. It is also possible that during walking, the relative impact of $\mathrm{BRP}$ on $\mathrm{VO}_{2}$ is lower than during running. Otherwise, at the time of the study, adolescents were participating in a daily exercise re-training programme based on lightto-moderate continuous exercise. The fatigue induced by these exercises may have increased the interindividual variability in the results, but we randomised the order of experiments so that this experimental bias was identical for each participant. Nevertheless, it should not be excluded that the limiting impact of BRP involves other physiological mechanisms that were not measured for practical reasons. First, some 
authors demonstrated that shuttle-running is associated with increased used of anaerobic metabolism (Ahmaidi et al., 1992; Buchheit et al., 2011). Second, obese adolescents are characterised by increased lower limb fatigability (Garcia-Vicencio et al., 2015) as well as impaired muscle oxidative capacities (Lazzer et al., 2013). Thus, the excessive recruitment of motor units would lead to the premature apparition of neuromuscular fatigue (Ratel et al., 2006) that would limit the continuation of the effort despite the fact that the cardiorespiratory system is still far from being limited. These muscular mechanisms, however, were not studied here, a deficiency that limits the current interpretation of our results.

Obese adolescents have difficulty achieving a maximal cardiorespiratory state (Thivel \& Aucouturier, 2015), especially during exercises that require body weight support, such as walking and running (Nantel et al., 2011). Continuous-shuttle tests are commonly used to assess functional aerobic capacities in obese children (Klijn et al., 2007; Quinart et al., 2014). Yet, these tests are difficult for this population. Although the difficulties associated with these tests are mentioned in several studies in the obese child (Nassis et al., 2005; Klijn et al., 2007; Castro-Pinheiro et al., 2011), none of them was interested in the physiological mechanisms that explain these limitations. Thus, measuring both physiological and psychological responses during shuttle versus straightline walking/running tests may highlight the potential mechanisms that can limit obese adolescents during the $20 \mathrm{~m}$ SRT and other shuttle-type exercises.

The second objective of the study was to compare the respiratory responses and RPE during an intermittent 15-15 protocol versus the C and C-BRP protocols at the same speeds $(3-6 \mathrm{~km} / \mathrm{h})$. The intermittent $15-15$ modality was used to design the Spartacus test, a graded intermittent protocol for evaluating aerobic functional capacities that has been validated in obese adolescents (Rey et al., 2016; Thivel et al., 2017). In line with our expectations, during 15-15, the $\mathrm{VO}_{2}$ was significantly lower than during the $\mathrm{C}$ and $\mathrm{C}$ BRP $(\mathrm{p}<0.05$ to $\mathrm{p}<0.001)$ at speeds above $3 \mathrm{~km} / \mathrm{h}$. These differences would correspond to 28,34 and $44 \%$ of the estimated $\mathrm{VO}_{2 \text { peak }}$ for this population at 4,5 and $6 \mathrm{~km} / \mathrm{h}$, respectively. These estimates suggest that $15-15$ walking at speeds $<7 \mathrm{~km} / \mathrm{h}$ is a lightintensity exercise for most severely obese adolescents; the addition of a previous landing at $6 \mathrm{~km} / \mathrm{h}$ could thus make the Spartacus test more accessible to adolescents who are severely obese. Intriguingly, the intensity of the effort appeared to increase more gradually during the 15-15 compared to the $\mathrm{C}$ and C-BRP protocols, despite the similar speed and stage durations. The more progressive nature of the 15-15 protocol could thus make it possible to more precisely identify the speeds that correspond to work intensities, a measure that is of major clinical interest.

During the passive recovery periods, the oxygen debt induced by the previous bout of exercise can be partially paid back, a phenomenon that would reduce breathlessness during the following bout of exercise. Whereas respiratory discomfort is a main limiting factor in obese individuals (Marinov et al., 2002), a short-interval-basedprotocol could help them to produce a cardiorespiratory test under more favourable respiratory conditions. From this perspective, the $15-15$ modality may be a strategy to delay fatigue in obese adolescents (Thivel et al., 2017) and encourage them to continue the test more than they would during the $20 \mathrm{~m}$ SRT. However, Rey et al. (2016) found that cardiorespiratory responses at the end of the test are not significantly different between the $20 \mathrm{~m}$ SRT and Spartacus test in obese adolescents. Although the Spartacus test induces a greater feeling of physical competence in this population (Rey et al., 2016), further comparisons between these two tests are needed to establish a scientific consensus as to which one more precisely assesses the maximum aerobic capacities of obese 
adolescents.

Finally, the RPE was assessed with the COPE-10, which was recently validated in obese youth (Quinart et al., 2016). Contrary to our expectations, there were no statistical differences between the 15-15 and either the C or C-BRP protocols regarding the RPE. With regards to the respiratory parameters, the stimulus provided by each protocol was probably insufficient to induce significant differences in the RPE score. This supposition was confirmed by the fact that the highest RPE observed in each protocol corresponded to moderate intensities (i.e., 3 to 4 out of 10 on the COPE-10 scale). Besides, the present results confirmed that the RPE assessed with COPE-10 is strongly associated with $\mathrm{VO}_{2}$ in obese adolescents (Quinart et al., 2014); however, the relationship between RPE and $\mathrm{VO}_{2}$ has not yet been studied during intermittent exercises in this population. This information would enable researchers and clinicians to determine under which exercise conditions the RPE is the lowest for a given intensity. On the other hand, it would also allow one to check whether this tool makes it possible to precisely target a work area during intermittent exercise. As expected, the relationship between RPE and $\mathrm{VO}_{2}$ was weaker in the $15-15(\mathrm{r}=0.49)$ compared to the $\mathrm{C}(\mathrm{r}=0.64)$ and $\mathrm{C}-\mathrm{BRP}(\mathrm{r}=$ $0.66)$ protocols $(\mathrm{p}<0.001$ for all protocols). The intermittent nature of the effort during 15-15 may cause more difficulty for obese adolescents to assess the intensity of their effort as precisely as during a continuous exercise.

Our results, and those from previous studies, suggest that intermittent modality exercises, with or without BRP, could promote adherence to physical activity programmes in obese adolescents. These exercises characterise many indoor disciplines, including team sports, and would allow significant improvements in aerobic capacities (Thivel et al., 2019) while promoting long-term maintenance of the obtained benefits (Tjönna et al., 2009). Thus, the inclusion of these activities in an exercise training programme for obese adolescents - who are clinically able to perform field activitiesappears to be justified both physiopathologically and psychologically. Overall, these results suggest that 1) poor performances during continuous shuttle-type tests in obese adolescents involve more muscular rather than respiratory factors and 2) the 15-15 modality may represent an intriguing alternative to the continuous test to encourage obese adolescents to achieve maximal respiratory effort.

\section{Limitations and future perspectives}

Our study has some limitations. First, paediatric obesity is a pathology characterised by many physiological and psychosocial factors that led to high individual variability in anthropometric characteristics and psychophysiological responses to the protocols in this study. In this context, studying the impact of individual factors, including training status, sex or maturation, on the studied parameters would require classifying adolescents according to their size, sex and maturation. However, the objective of this study was to compare respiratory and perceptual responses to different incremental protocols for a group of severely obese adolescents; the impact of individual factors on these parameters may be the subject of a future study with a larger sample. The variability in the age and degree of obesity among adolescents following a hospital-based treatment programme have already been discussed by Rey et al. (2016). These factors must be considered when an exercise training programme is conducted with a group. Second, our interpretation is limited to submaximal data; it would be interesting to measure the maximal cardiorespiratory responses as a function of the type of protocol. Finally, body composition was assessed using impedancemetry, which is not accurate in severely obese 
Continuous vs. intermittent walking in obese adolescents adolescents (Thivel et al., 2018). 


\section{Conclusion}

In conclusion, the presence of two BRP per min did not significantly impact the respiratory responses or RPE at speeds between 3 and $6 \mathrm{~km} / \mathrm{h}$. During 15-15 walking, the respiratory responses were significantly lower than during the $\mathrm{C}$ and $\mathrm{C}$-BRP protocols at 4,5 and $6 \mathrm{~km} / \mathrm{h}(\mathrm{p}<0.05, \mathrm{p}<0.01$ and $\mathrm{p}<0.001$, respectively). RPE was generally unaffected by the protocol. Finally, the relationship between $\mathrm{RPE}$ and $\mathrm{VO}_{2}$ was greater in the $\mathrm{C}(\mathrm{r}=0.64, \mathrm{p}<0.001)$ and C-BRP $(\mathrm{r}=0.66, \mathrm{p}<0.001)$ compared to the $15-15$ protocol $(\mathrm{r}=0.49, \mathrm{p}<0.001)$. The respiratory impact of sudden directional changes during a $20 \mathrm{~m}$ SRT would be minor at walking speeds. In comparison to continuous protocols, the 15-15 protocol allows obese adolescents to reduce their respiratory responses by 15 $25 \%$ at speeds above $3 \mathrm{~km} / \mathrm{h}$.

\section{Aknowledgements}

We are very grateful to the teenagers and the team of the Zuydcoote Maritime Hospital's Rehabilitation Care Unit for their hospitality and participation in the study. We sincerely thank the Metropolitan Côte d'Opale (PMCO) for financial support.

Conflict of interest

The authors report no conflict of interest.

Words: 4152 


\section{References}

Ahmaidi, S., Collomp, K., \& Préfaut, C. (1992). The effect of shuttle test protocol and the resulting lactacidaemia on maximal velocity and maximal oxygen uptake during the shuttle exercise test. European Journal of Applied Physiology and Occupational Physiology, 65(5), 475-479. https://doi.org/10.1007/BF00243517

Barry, V. W., Baruth, M., Beets, M. W., Durstine, J. L., Liu, J., \& Blair, S. N. (2014). Fitness vs. fatness on all-cause mortality: a meta-analysis. Progress in Cardiovascular Diseases, 56(4), 382-390. https://doi.org/10.1016/j.pcad.2013.09.002.

Berthoin, S., Gerbeaux, M., Turpin, E., Guerrin, F., Lensel-Corbeil, G., \& Vandendorpe, F. (1994). Comparison of two field tests to estimate maximum aerobic speed. Journal of Sports Sciences, 12(4), 355-362.

https://doi.org/10.1080/02640419408732181

Breithaupt, P. G., Colley, R. C., \& Adamo, K. B. (2012). Using the oxygen uptake efficiency slope as an indicator of cardiorespiratory fitness in the obese pediatric population. Pediatric Exercise Science, 24(3), 357-368. https://doi.org/10.1123/pes.24.3.357.

Buchheit, M., Haydar, B., Hader, K., Ufland, P., \& Ahmaidi, S. (2011). Assessing running economy during field running with changes of direction: application to $20 \mathrm{~m}$ shuttle runs. International Journal of Sports Physiology and Performance, 6(3), 380395.

Castro-Piñeiro, J., Ortega, F. B., Keating, X. D., González-Montesinos, J. L., Sjöstrom, M., \& Ruiz, J. R. (2011). Percentile values for aerobic performance running/walking field tests in children aged 6 to 17 years: influence of weight status. Nutricion Hospitalaria, 26(3), 572-578. https://doi.org/10.3305/nh.2011.26.3.4597

Compher, C., Frankenfield, D., Keim, N., \& Roth-Yousey, L. (2006). Best practice methods to apply to measurement of resting metabolic rate in adults: a systematic review. Journal of the American Dietetic Association, 106(6), 881-903. https://doi.org/10.1016/j.jada.2006.02.009

Dellal, A., Keller, D., Carling, C., Chaouachi, A., Wong, D. P., \& Chamari, K. (2010). Physiologic effects of directional changes in intermittent exercise in soccer players. Journal of Strength and Conditioning Research, 24(12), 3219-3226. https://doi.org/10.1519/JSC.0b013e3181b94a63

Di Prampero, P. E. (1986). The energy cost of human locomotion on land and in water. International Journal of Sports Medicine, 7(2), 55-72. https://doi.org/10.1055/s-20081025736

Fawkner, S., \& Armstrong, N. (2003). Oxygen uptake kinetic response to exercise in children. Sports Medicine, 33(9), 651-669. https://doi.org/10.2165/00007256200333090-00002

Garcia-Vicencio, S., Martin, V., Kluka, V., Cardenoux, C., Jegu, A. G., Fourot, A. V., ... Ratel, S. (2015). Obesity-related differences in neuromuscular fatigue in adolescent girls. European Journal of Applied Physiology, 115(11), 2421-2432.

https://doi.org/10.1007/s00421-015-3222-9

Hatamoto, Y., Yamada, Y., Sagayama, H., Higaki, Y., Kiyonaga, A., \& Tanaka, H. 
(2014). The relationship between running velocity and the cost of running of turning during running. PLoS One, 9(1). https://doi.org/10.1371/journal.pone.0081850

He, Q. Q., Wong, T. W., Du, L., Jiang, Z. Q., Qiu, H., Gao, Y., ... Yu, I. T. S. (2009). Respiratory health in overweight and obese Chinese children. Pediatric Pulmonology, 44(10), 997-1002. https://doi.org/10.1002/ppul.21091

Klijn, P. H. C., van der Baan-Slootweg, O. H., \& van Stel, H. F. (2007). Aerobic exercise in adolescents with obesity: Preliminary evaluation of a modular training program and the modified shuttle test. BMC Pediatrics, 7. https://doi.org/10.1186/14712431-7-19.

Kvaavik, E., Klepp, K.-I., Tell, G. S., Meyer, H. E., \& Batty, G. D. (2008). Physical fitness and physical activity at age 13 years as predictors of cardiovascular disease risk factors at ages 15, 25, 33, and 40 years: extended follow-up of the Oslo Youth Study. Pediatrics, 123(1), e80-e86. https://doi.org/10.1542/peds.2008-1118

Lazaar, N., Aucouturier, J., Ratel, S., Rance, M., Bedu, M., \& Duché, P. (2006). Influence d'un programme d'activité physique sur la perception de la contrainte de l'exercice chez le jeune enfant obèse vs non obèse. Science and Sports, 21(2), 104106. https://doi.org/10.1016/j.scispo.2005.06.003

Lazzer, S., Salvadego, D., Porcelli, S., Rejc, E., Agosti, F., Sartorio, A., \& Grassi, B. (2013). Skeletal muscle oxygen uptake in obese patients: functional evaluation by kneeextension exercise. European Journal of Applied Physiology, 113(8), 2125-2132. https://doi.org/10.1007/s00421-013-2647-2

Léger, L., Lambert, J., Goulet, A., Rowan, C., \& Dinelle, Y. (1984). Aerobic capacity of 6 to 17-year-old Quebecois--20 meter shuttle run test with 1 minute stages. Canadian Journal of Applied Sport Sciences, 9(2), 64-69.

Marinov, B., Kostianev, S., \& Turnovska, T. (2002). Ventilatory efficiency and rate of perceived exertion in obese and non-obese children performing standardized exercise.

Clinical Physiology and Functional Imaging, 22(4), 254-260.

https://doi.org/10.1046/j.1475-097X.2002.00427.x

Mendelson, M., Michallet, A. S., Estève, F., Perrin, C., Levy, P., Wuyam, B., \& Flore, P. (2012). Ventilatory responses to exercise training in obese adolescents. Respiratory Physiology and Neurobiology, 184(1), 73-79.

https://doi.org/10.1016/j.resp.2012.08.001

Morinder, G., Mattsson, E., Sollander, C., Marcus, C., \& Larsson, U. E. (2009). Sixminute walk test in obese children and adolescents: Reproducibility and validity. Physiotherapy Research International, 14(2), 91-104. https://doi.org/10.1002/pri.428

Nantel, J., Brochu, M., \& Prince, F. (2006). Locomotor strategies in obese and nonobese children. Obesity, 14(10), 1789-1794. https://doi.org/10.1038/oby.2006.206

Nassis, G. P., Psarra, G., \& Sidossis, L. S. (2005). Central and total adiposity are lower in overweight and obese children with high cardiorespiratory fitness. European Journal of Clinical Nutrition, 59(1), 137-141. https://doi.org/10.1038/sj.ejcn.1602061

Norman, A.-C. (2005). Influence of excess adiposity on exercise fitness and performance in overweight children and adolescents. Pediatrics, 115(6), e690-e696. https://doi.org/10.1542/peds.2004-1543 
O’Malley, G., Hussey, J., \& Roche, E. (2012). A pilot study to profile the lower limb musculoskeletal health in children with obesity. Pediatric Physical Therapy, 24(3), 292-298. doi: 10.1097/PEP.0b013e31825c14f8.

Ortega, F. B., Ruiz, J. R., Castillo, M. J., \& Sjöström, M. (2008). Physical fitness in childhood and adolescence: a powerful marker of health. International Journal of Obesity. 32(1), 1-11. https://doi.org/10.1038/sj.ijo.0803774

Ortega, F. B., Labayen, I., Ruiz, J. R., Kurvinen, E., Loit, H. M., Harro, J., ... Sjöström, M. (2011). Improvements in fitness reduce the risk of becoming overweight across puberty. Medicine and Science in Sports and Exercise, 43(10), 1891-1897. https://doi.org/10.1249/MSS.0b013e3182190d71

Peyrot, N., Thivel, D., Isacco, L., Morin, J.-B., Duche, P., \& Belli, A. (2009). Do mechanical gait parameters explain the higher metabolic cost of walking in obese adolescents? Journal of Applied Physiology, 106(6), 1763-1770.

https://doi.org/10.1152/japplphysiol.91240.2008

Quinart, S., Groslambert, A., Ecarnot, F., Simon-Rigaud, M.-L., Nicolet-Guénat, M., Nègre, V., \& Mougin, F. (2016). Validation of a new scale to measure perceived exertion in obese adolescents: The Childhood Obesity Perceived Exertion (Cope-10) Scale. Journal of Sports Medicine and Physical Fitness, 56(9), 1013-1020.

Quinart, S., Mougin, F., Simon-Rigaud, M. L., Nicolet-Guénat, M., Nègre, V., \& Regnard, J. (2014). Evaluation of cardiorespiratory fitness using three field tests in obese adolescents: Validity, sensitivity and prediction of peak VO2. Journal of Science and Medicine in Sport, 17(5), 521-525. https://doi.org/10.1016/j.jsams.2013.07.010

Rey, O., Rossi, D., Nicol, C., Mercier, C. S., Vallier, J. M., \& Maïano, C. (2013). Évaluation indirecte de la capacité aérobie d'adolescents obèses: Intérêt d'un test de course à pied intermittent court, progressif et maximal. Science and Sports, 28(5). https://doi.org/10.1016/j.scispo.2013.02.006

Rey, O., Maïano, C., Nicol, C., Mercier, C. S., \& Vallier, J. M. (2016). Psychophysiological responses of obese adolescents to an intermittent run test compared with a 20-m shuttle run. Journal of Sports Science and Medicine, 15(3), 451-459. https://doi.org/10.1177/0959683607082551

Rolland-Cachera MF1, Cole TJ, Sempé M, Tichet J, Rossignol C, C. A. (1991). Body Mass Index variations: centiles from birth to 87 years. European Journal of Clinical Nutrition, 45(1), 13-21. https://doi.org/10.1002/mbo3.272

Rosenbaum, M., Vandenborne, K., Goldsmith, R., Simoneau, J.-A., Heymsfield, S., Joanisse, D. R., ... Leibel, R. L. (2003). Effects of experimental weight perturbation on skeletal muscle work efficiency in human subjects. American Journal of Physiology Regulatory, Integrative and Comparative Physiology, 285(1), R183-R192. https://doi.org/10.1152/ajpregu.00474.2002

Rossi D., Mauffrey D., Nicol C. (2009). Présentation d'un protocole de test d'aptitude à l'effort aérobie, Revue Hyper-EPS, 244, 4-9.

Salvadego, D., Lazzer, S., Busti, C., Galli, R., Agosti, F., Lafortuna, C., ... Grassi, B. (2010). Gas exchange kinetics in obese adolescents. Inferences on exercise tolerance and prescription. AJP: Regulatory, Integrative and Comparative Physiology, 299(5), R1298-R1305. https://doi.org/10.1152/ajpregu.00038.2010 
Sheehan, K., \& Gormley, J. (2012). Gait and increased body weight (potential implications for musculoskeletal disease). Physical Therapy Reviews, 17(2), 91-98. https://doi.org/10.1179/1743288x11y.0000000057

Thivel, D., O’Malley, G., Blourdier, D., Tremeaux, M., Zanchet, C., Pereira, B., \& Ratel, S. (2017). Reproducibility of the intermittent Spartacus Run Test in obese adolescents. The Journal of Sports Medicine and Physical Fitness, 57(9), 1083-1088. https://doi.org/10.23736/S0022-4707.16.06534-8

Thivel D, Aucouturier J. (2015) Cardiorespiratory fitness evaluation in obese youth. In M.L. Frelut (Ed.), The ECOG's eBook on Child and Adolescent Obesity. Retrieved from ebook.ecog-obesity.eu

Thivel, D., Verney, J., Miguet, M., Masurier, J., Cardenoux, C., Lambert, C., ... Pereira, B. (2018). The accuracy of bioelectrical impedance to track body composition changes depends on the degree of obesity in adolescents with obesity. Nutrition Research, 54, 60-68. https://doi.org/10.1016/j.nutres.2018.04.001

Thivel, D., Isacco, L., O’Malley, G., \& Duché, P. (2016). Pediatric Obesity and Perceived Exertion: Difference Between Weight-Bearing and Non-Weight-Bearing Exercises Performed at Different Intensities. Journal of Sports Sciences, 34(5), 389394. https://doi.org/10.1080/02640414.2015.1061200

Thivel, D., Masurier, J., Baquet, G., Timmons, B. W., Pereira, B., Berthoin, S., ... Aucouturier, J. (2019). High-intensity interval training in overweight and obese children and adolescents: Systematic review and meta-analysis. Journal of Sports Medicine and Physical Fitness, 59(2), 310-324. https://doi.org/10.23736/S0022-4707.18.08075-1

Tjønna, A. E., Stølen, T. O., Bye, A., Volden, M., Slördahl, S. A., Ødegård, R., ... Wisløff, U. (2009). Aerobic interval training reduces cardiovascular risk factors more than a multitreatment approach in overweight adolescents. Clinical Science, 116(4), 317-326. https://doi.org/10.1042/CS20080249

Tomkinson, G. R., Lang, J. J., Tremblay, M. S., Dale, M., Leblanc, A. G., Belanger, K., ... Léger, L. (2017). International normative $20 \mathrm{~m}$ shuttle run values from 1142026 children and youth representing 50 countries. British Journal of Sports Medicine, 51(21), 1545-54. https://doi.org/10.1136/bjsports-2016-095987

Twig, G., Yaniv, G., Levine, H., Leiba, A., Goldberger, N., Derazne, E., ... Kark, J. D. (2016). Body-mass index in 2.3 million adolescents and cardiovascular death in adulthood. New England Journal of Medicine, 374(25), 2430-2440.

https://doi.org/10.1056/nejmoa1503840

Vanhelst, J., Fardy, P. S., Salleron, J., \& Béghin, L. (2013). The six-minute walk test in obese youth: reproducibility, validity, and prediction equation to assess respiratory power. Disability and Rehabilitation, 35(6), 479-482.

https://doi.org/10.3109/09638288.2012.699581

Vincent, H. K. (2015). Advising the obese patient on starting a running program.

Current Sports Medicine Reports, 14(4), 278.

https://doi.org/10.1249/jsr.0000000000000171 
Continuous vs. intermittent walking in obese adolescents

Table 1. Participant characteristics, presented as mean \pm standard deviation (SD) values.

\begin{tabular}{|l|l|l|l|}
\hline & Girls $(\mathrm{n}=12)$ & Boys $(\mathrm{n}=7)$ & Total $(\mathrm{n}=19)$ \\
\hline Age (yrs) & $15.7(1.1)$ & $14.4(1.6)$ & $15.2(1.5)$ \\
BMI (kg.m $\left.{ }^{-2}\right)$ & $39.4(4.7)$ & $40.2(7.7)$ & $39.7(5.9)$ \\
Z-Score BMI (SD) & $2.4(0.2)$ & $2.6(0.3)$ & $2.5(0.2)$ \\
Total mass (kg) & $103.0(14.2)$ & $117.1(33.6)$ & $108.2(24.3)$ \\
Lean mass (\%) & $53.5(2.8)$ & $59.6(8.2)$ & $55.7(6.2)$ \\
Fat mass (\%) & $46.4(2.8)$ & $40.4(8.2)$ & $44.3(6.2)$ \\
\hline
\end{tabular}


Figure 1: Representation of the three protocols for 1 min of exercise. Abbreviations: run $=$ exercise; rec $=$ passive recovery; $\mathrm{C}=$ continuous walking $; \mathrm{C}-\mathrm{BRP}=$ continuous walking that require turning back every 30 seconds; $15-15=$ successive periods of walking and passive recovery of 15 seconds.

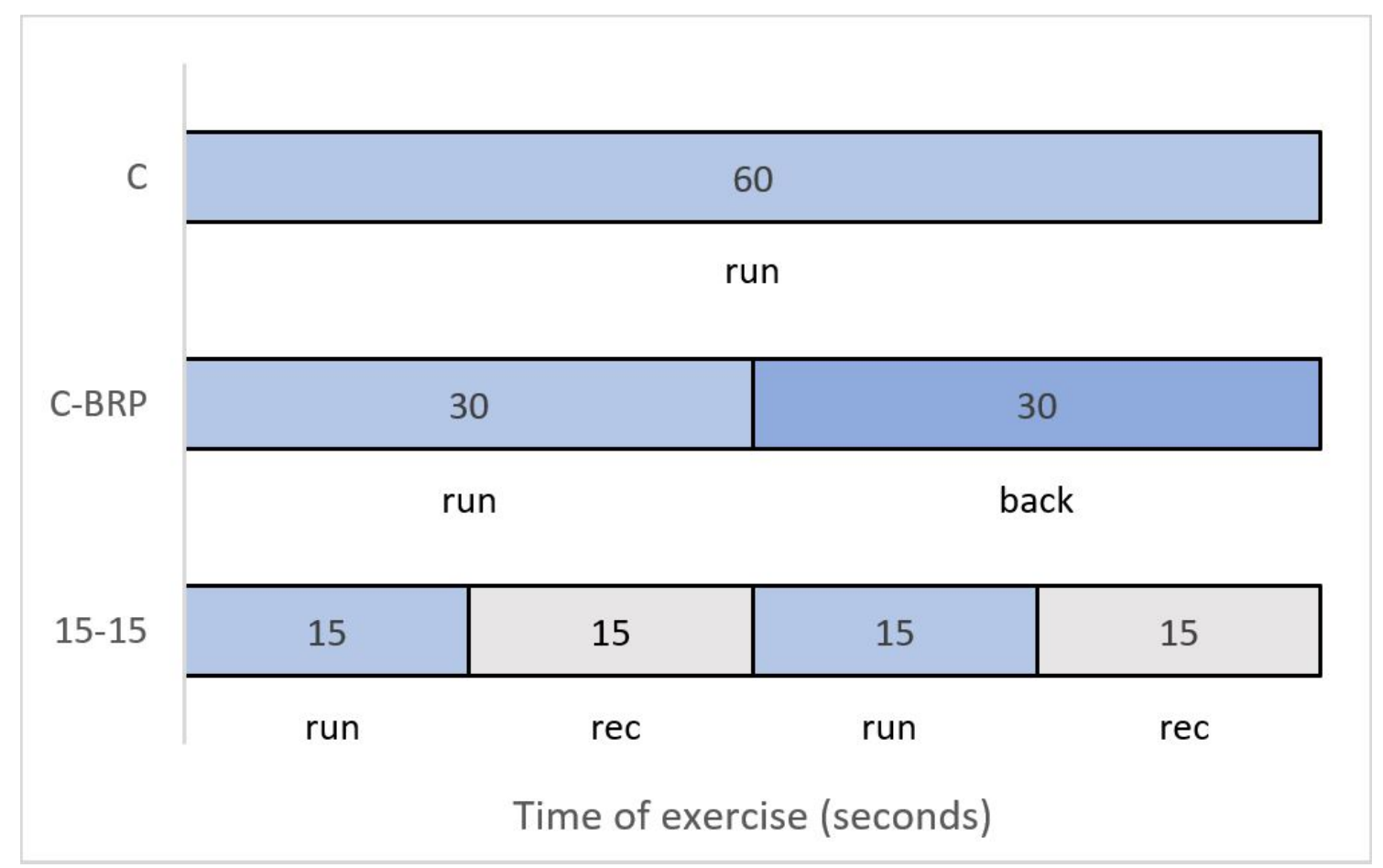


Figure 2. Oxygen uptake $\left(\mathrm{VO}_{2}\right)$ as a function of speed for each protocol. Differences between 15-15 and C: * $(\mathrm{p}<0.05)$; ** $(\mathrm{p}<0.01)$; *** $(\mathrm{p}<0.001)$. Differences between 15-15 and C-BRP: ${ }^{\circ}(\mathrm{p}<0.05) ;{ }^{\circ}(\mathrm{p}<0.01) ;{ }^{\circ \circ \circ}(\mathrm{p}<0.001)$.

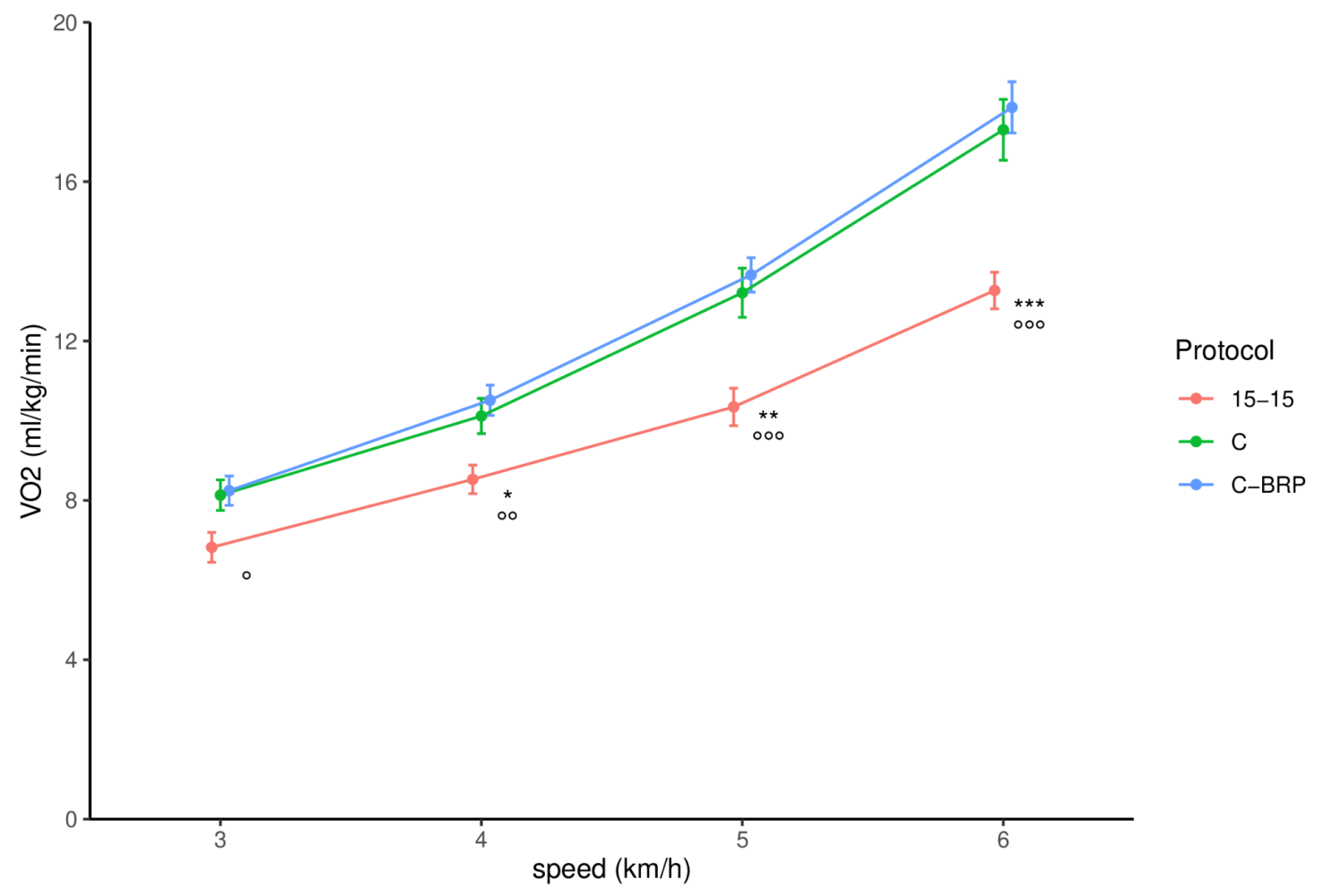


Figure 3. Aerobic cost of walking $(\mathrm{Cw})$ as a function of speed for each protocol. Differences between 15-15 and C: $*(\mathrm{p}<0.05) ; * *(\mathrm{p}<0.01) ; * * *(\mathrm{p}<0.001)$. Differences between 15-15 and C-BRP: ${ }^{\circ}(\mathrm{p}<0.05){ }^{\circ \circ}(\mathrm{p}<0.01){ }^{\circ \circ}{ }^{\circ}(\mathrm{p}<0.001)$.

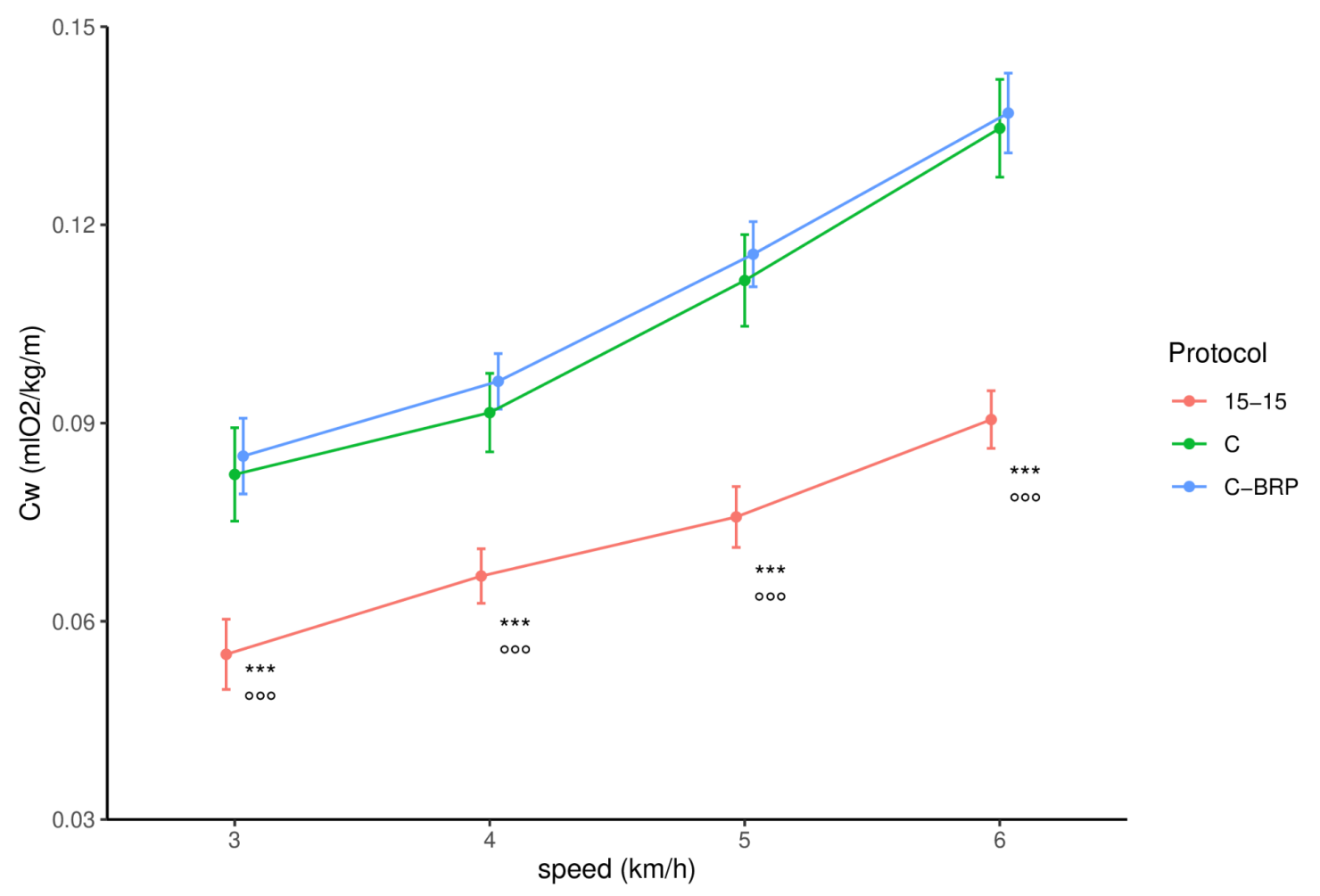


Figure 4. Rating of perceived exertion (RPE) as a function of speed for each protocol. Differences between 15-15 and C: * $(\mathrm{p}<0.05)$; ** $(\mathrm{p}<0.01)$; *** $(\mathrm{p}<0.001)$. Differences between 15-15 and C-BRP: ${ }^{\circ}(\mathrm{p}<0.05) ;{ }^{\circ}(\mathrm{p}<0.01) ;{ }^{\circ \circ \circ}(\mathrm{p}<0.001)$.

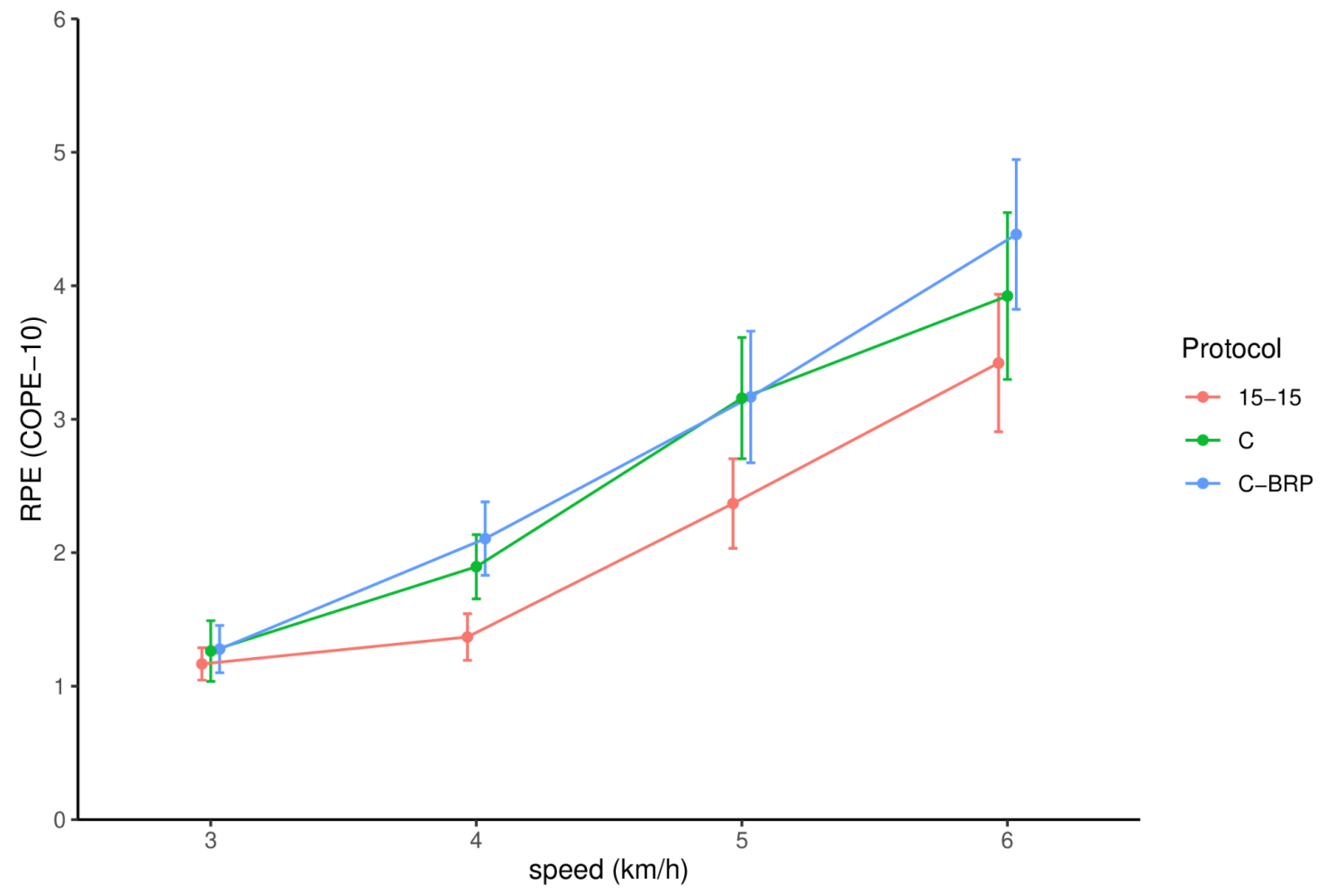

